\title{
THE VALUE OF SPLENECTOMY IN FANCONI'S ANAEMIA
}

\author{
BY \\ R. C. FRANCIS, R. A. MOIR and P. N. SWIFT \\ From Orpington Hospital, Kent, and St. Bartholomew's Hospital, Rochester
}

(RECEIVED FOR PUBLICATION JUNE 5, 1955)

The syndrome described by Fanconi (1927), which consists of hypoplastic anaemia, multiple anatomical defects and pigmentation of the skin is now well recognized though uncommon; some 28 cases have been recorded.

This report is made with the object, not only of placing on record the features of two cases, but of examining the place of splenectomy in treatment. In nine instances splenectomy has now been performed and the results have been unsatisfactory. Opinions as to the value of operation and the indications for performing it differ, though it is generally agreed to be valueless if marrow hypoplasia is extreme.

\section{Case Report}

Dorothy M., aged 8 (born on June 13, 1944), was the only child of a second marriage. There were four children from previous marriages of her parents, and these children were all normal. There was no history of anaemia or congenital abnormality in any other member of the family. The parents of the child were healthy and their blood counts were normal.

She had always been well, apart from an attack of measles, followed by pneumonia, when she was aged 6 . The parents denied that she was ever lacking in energy, and had not noticed that her appearance was in any way unusual. A month before admission, she had bled from the nose and throat for two days, and had been pale ever since.

On admission, the child was found to be very small. She weighed $32 \mathrm{lb}$. Her height was $3 \mathrm{ft} .6 \mathrm{in}$. and her skull circumference $17 \frac{1}{2}$ in. She was deeply pigmented all over, the colour being a dark, smoky brown. This was most marked on the abdomen and in the flexures, where there were patches of deeper pigmentation. Her eyes were very small, with a mongolian slant, and there was no strabismus. Her appearance was completely unlike that of any other member of the family. Her right thumb was extremely small, but fully functional. There was no other skeletal abnormality. Radiographs showed no changes in the skull, thoracic cage or long bones.

No abnormality could be found in the heart or lungs, and there was no lymphadenopathy, splenomegaly or hepatomegaly. There was no abnormality of the external urogenital system and the central nervous system appeared normal.

Investigations. A full blood count gave: haemoglobin, $37 \%(5.4$ g. $\%)$; red blood cells, 1.52 million; colour index, $1 \cdot 23$; white blood cells 6,400 (polymorphs $29 \%$, lymphocytes $66 \%$, monocytes $3 \%$, basophils $2 \%$, reticulocytes $4 \cdot 4 \%$ ). Red blood cells showed anisocytosis and poikilocytosis. Cells were fully haemoglobinized. There were no spherocytes, target cells or sickle cells.

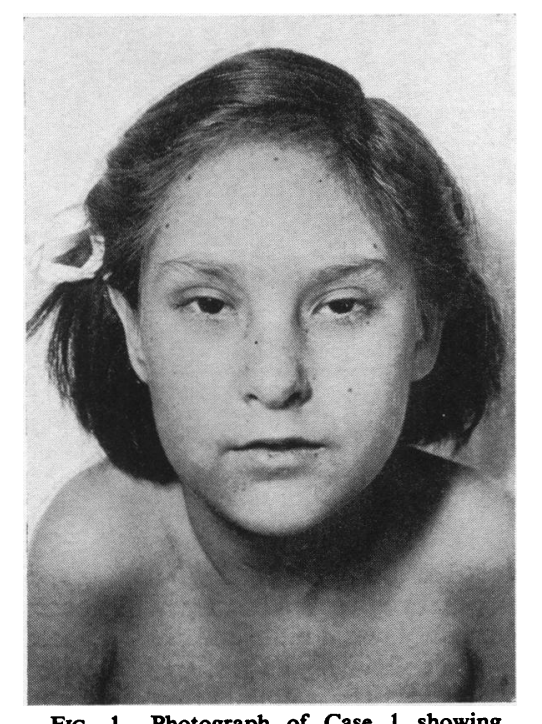

FIG. 1.-Photograph of Case 1 showing micro-ophthalmos, microcephaly and pigmentation.

Haemolysis was incomplete at $0.45 \%$, complete at $0.3 \%$. The direct Coombs test was negative and no warm or cold agglutinins were detected by Dacie's method. The erythrocyte sedimentation rate was $51 \mathrm{~mm}$. in one hour, the bleeding time 7 minutes 30 seconds, clotting time 2 minutes 30 seconds, platelets 50,000 per c.mm.

Marrow examination gave total cells 9,000 (neutrophils, segmented $8.0 \%$, unsegmented $2 \cdot 0 \%$, metamyelocytes $3.0 \%$, myelocytes $3.5 \%$, promyelocytes $0.5 \%$, 
eosinophils $0.5 \%$; smear cells and naked nuclei $11.5 \%$, lymphocytes $43.0 \%$, monocytes $2 \cdot 5 \%$, promonocytes $0.5 \%$. Normoblasts: late, $4.0 \%$; intermediate, $12.0 \%$; early, $8 \cdot 5 \%$. Total: $24.5 \%$. Cells in mitosis, $0.5 \%$. Myeloid-erythroid ratio, $0 \cdot 7: 1$.

The low total nuclear count and the high proportion of lymphocytes indicated greatly depressed marrow activity, and the low myeloid-erythroid ratio that myeloid activity was at a very low ebb indeed. There were no abnormal cell types. delayed. The shadow of the right kidney was seen to overlie the left sacro-iliac joint. No excretion could be seen anywhere on the right side.

Serum electrolytes were normal. The sterone and 17-ketosteroid content of the urine was within normal limits. There was no steatorrhoea.

Although the child appeared well, after two weeks the white cells dropped to 1,600 (polymorphs $31 \%$, lymphocytes $66 \%$, monocytes $3 \%$ ). Platelets fell to 17,000 and the bleeding time rose to $8 \frac{1}{2}$ minutes. She developed

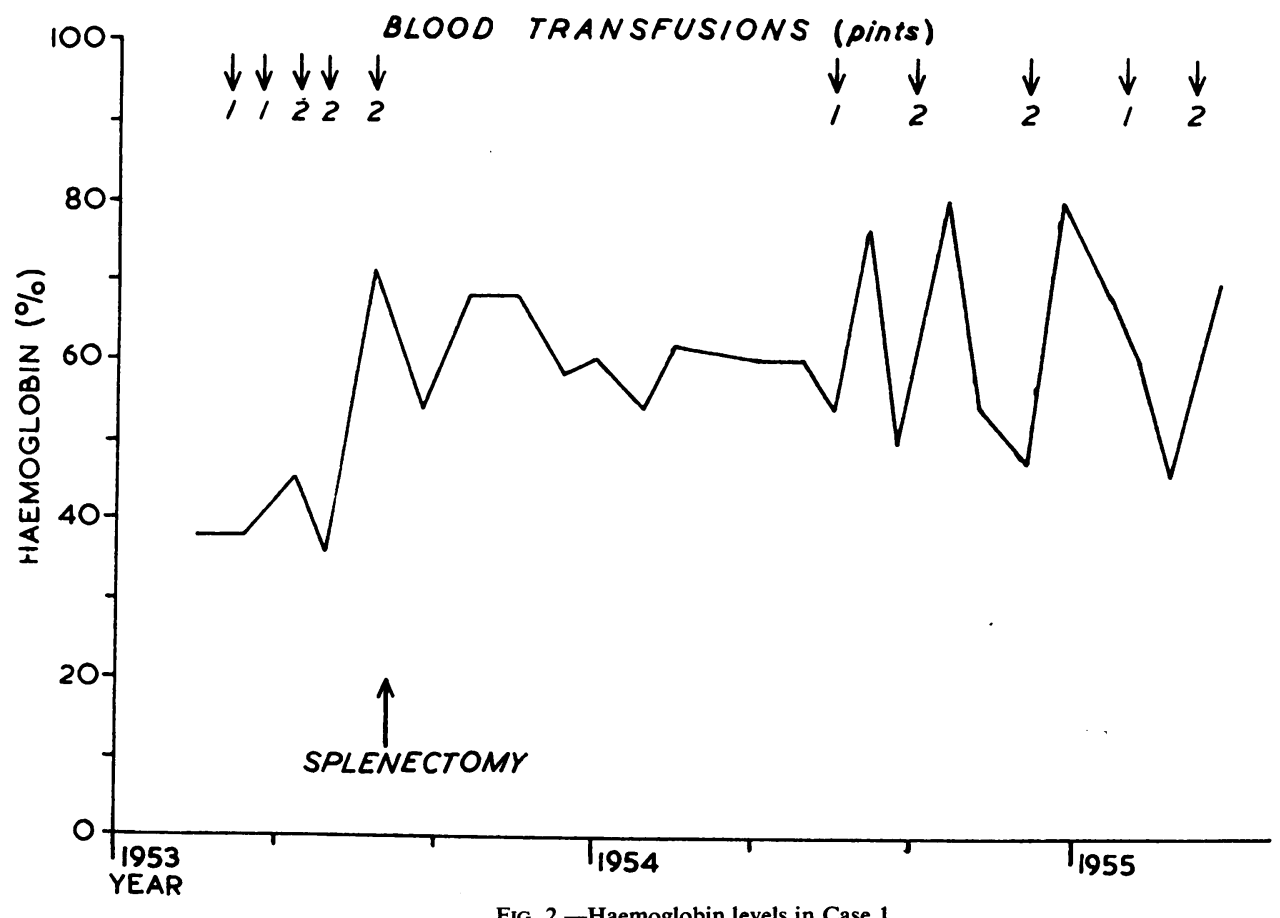

Fig. 2.-Haemoglobin levels in Case 1.

The blood urea level was $31 \cdot 3 \mathrm{mg}$. $\%$, and the serum cholesterol $310 \mathrm{mg}$. \%. The direct Van den Bergh test was negative, the indirect within normal limits. Thymol turbidity was 4 units and zinc sulphate turbidity 2 units. The colloidal gold test was negative.

Urine. There was a faint trace of albumin, no reducing substances, bile pigments or salts. Urobilinogen was absent and there was no phosphaturia, cystinuria or tyrosinuria. Microscopy revealed no abnormality and culture was sterile.

The stools were frequently examined, and were always negative for occult blood.

Section of skin showed an increased amount of pigment in the cells of the basal and prickle layers of the epidermis. There was a large proportion of pigment containing macrophages in the corium, just under the epidermis.

An intravenous pyelogram showed that excretion was patches of purpura on the arms, abdomen and legs, and vomited bloodstained mucus. Following transfusion her blood picture continued to deteriorate and necessitated frequent further transfusions. She developed epistaxis, and one attack of acute abdominal pain, after which her stools contained occult blood. A course of cortisone was tried, but had no effect whatever on haemopoiesis. A further bone marrow examination three months later showed a marked increase in erythroblastic activity compared with the previous examination. Myeloid activity was still reduced. Frequent reticulocyte counts showed a variation between $1 \cdot 2 \%$ and $6 \cdot 8 \%$. In view of the low bone marrow activity, and the fact that the child was needing transfusions every three weeks, it was decided to undertake splenectomy.

The operation was performed on July 21, 1953, by Mr. Stanley. A normal-sized spleen was removed with ease. 
Section of the spleen showed well developed lymph follicles with active germ centres. The pulp was highly cellular, with prominent sinuses in which the littoral cells were hyperplastic. Free and phagocytosed blood-pigment was plentiful. There was no erythroid hyperplasia and no erythrophagocytosis.

During the week preceding the operation the patient was given 1 pint of blood and 1 pint of packed red cells. Immediately after the operation the blood count was:

Red blood cells $2,640,000$, haemoglobin $65 \%$, white blood cells 1,200 (lymphocytes $40 \%$, polymorphs $57 \%$, eosinophils $1 \%$, monocytes $2 \%$, reticulocytes $3 \%$ ).

This picture gradually improved without further treatment, until one month after the operation, when the blood picture was: Red blood cells 3,040,000, haemoglobin $68 \%$, white blood cells 3,200 , lymphocytes $60 \%$, polymorphs $39 \%$, monocytes $1 \%$.

Her blood picture from then on varied as shown on the graph, but nine months after the operation the red cell count had fallen to $1,670,000$. She had remained asymptomatic during this period. She was re-admitted and transfused with 1 pint of whole blood. Three months later she was re-admitted with pain in the back and high pyrexia. The blood count was then: red cells $2,400,000$ and haemoglobin $48 \%$.

There was marked bruising of both legs, but the condition settled down after further transfusions. She has needed further transfusions at diminishing intervals.

Case 2. Ian L., aged 5 (born on November 29, 1948), was an only child. He had had the common exanthemata mildly, but had otherwise been in good health until three months before admission when recurrent epistaxis had developed.

The mother and father were well and there had been no other pregnancies. There was no consanguinity and no knowledge of any condition resembling that of our patient in the family (two cousins, two aunts, one uncle, five in the grandparent's and three in the great grandparent's generations). One maternal second cousin is said to have died at the age of 18 but the cause was not known. The only abnormality found in the parents was in the father who had an area of vitiligo measuring 2 in. $\times 1$ in. over the epigastrium. Their blood counts were normal.

The boy was admitted to hospital on October 10, 1953, on account of a profuse epistaxis following a head cold. The haemoglobin had fallen to $3.3 \mathrm{~g}$. per $100 \mathrm{ml}$. (22\%) and an immediate transfusion of 2 pints ( 1.3 litres) of whole blood was given. The only other haemorrhagic manifestation was bruising over the left tibia which may well have been traumatic in origin.

He was a small child for his age with an immature appearance and fair complexion. His height was $3 \mathrm{ft} .2$ in. $(96 \cdot 6 \mathrm{~cm}$.), weight $27 \mathrm{lb}$. $(12 \cdot 2 \mathrm{~kg}$.), skull circumference $19 \frac{1}{2}$ in. $(52.5 \mathrm{~cm}$.). Weight was $4 \mathrm{lb} .2 \mathrm{oz}$. at birth (one month premature).

Areas of light brown pigmentation were present on the right cheek and abdomen and a clearly defined area of depigmentation on the epigastrium.

The right wrist was in valgus deformity and the cor- responding thumb absent. The left upper limb was normal except for a small but fully functional thumb.

Radiologically the right first rib and humerus were narrower than those on the left. The right radius was shortened with malformed and rounded metaphyses. The right ulna showed a similar deformity and in addition

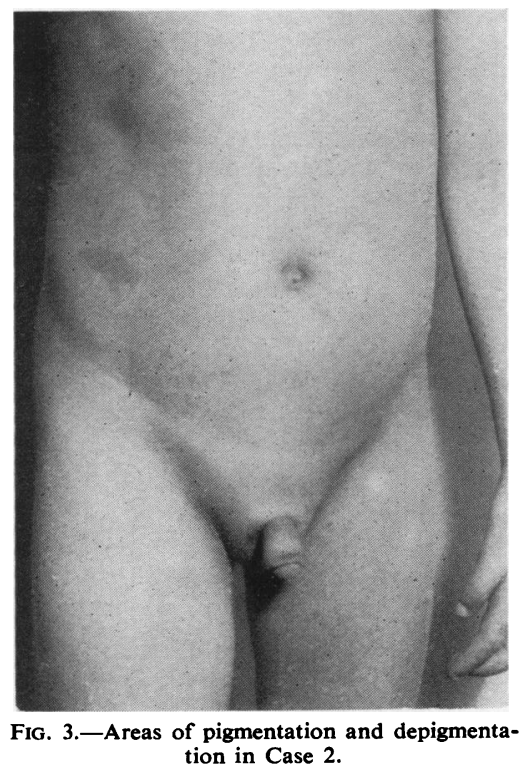

curvature of its shaft, greatest about one inch below the head. Neither lower epiphysis was visible. Two ossification centres were present in each carpus but none to indicate skeletal rudiments of a right thumb. The metacarpal and phalangeal bones of the right were narrower than those of the left hand.

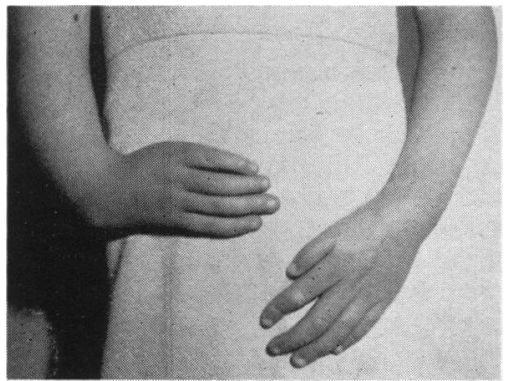

Fig. 4.-Deformity of forearms and hands in Case 2.

Over the precordium and loudest in the third left interspace a rough systolic murmur was audible, but unaccompanied by any alteration in the intensity or quality of the heart sounds or abnormality in shape or size of the heart. Blood pressure was $100 / 70 \mathrm{~mm}$. $\mathrm{Hg}$. 
Examination of the ocular, nervous, external urogenital and respiratory systems was negative. His intelligence, though not formally estimated, was considered normal for his age.

Investigations. A blood count on December 10, 1953, gave the following results: Red blood cells 2,500,000 per c.mm., cells showing anisocytosis and polychromasia, haemoglobin $8.5 \mathrm{~g} . / 100 \mathrm{ml}$., colour index $1 \cdot 2$, P.C.V. $24 \%$, reticulocytes $0.8 \%$, white blood cells 3,000 per c.mm. (neutrophils 1,440, monocytes 120, lymphocytes 1,440). E.S.R. (Westergren) $25 \mathrm{~mm} . / \mathrm{hr}$., platelets 47,000 per c.mm., bleeding time 5 minutes, clotting time 5-9 minutes, prothrombin time $14 \mathrm{sec}$. (control $14 \mathrm{sec}$.).

A total nucleated count of the tibial marrow on November 13 was 5,000:

$\left.\begin{array}{llll}\begin{array}{l}\text { Leukoblasts .. } \\ \text { Promyelocytes }\end{array} & \ldots & \ldots & 0 \cdot 5 \% \\ \begin{array}{l}\text { Myelocytes .. } \\ \text { Metamyelocytes }\end{array} & \ldots & \ldots & 11 \cdot 5 \\ \begin{array}{l}\text { Neutrophil } \\ \text { Eosinophil }\end{array} & \ldots & \ldots & 12 \\ \text { Lymphocytes } & \ldots & \ldots & 33 \cdot 5 \\ \text { Ly } & \ldots & \ldots & 6 \cdot 5 \%\end{array}\right\} 59 \cdot 5 \%$

On an intravenous pyelogram the position and shape of the right kidney and ureter were normal. The left ureter was visualized only in the pelvis and no renal shadow was seen, indicating that this kidney was functional but displaced downwards and overlying the sacro-iliac joint.

An analysis of the urine showed: Albumin $15 \mathrm{mg} . \%$, reducing substances nil, a few R.B.C.s only and no casts.

A serum protein estimation gave: albumin $4.5 \mathrm{~g}$. $\%$, globulin $2.0 \mathrm{~g} . \%$, fibrinogen $0.3 \mathrm{~g} . \%$.

Serum cholesterol was $155 \mathrm{mg}$. \%.

His clinical condition improved satisfactorily after the initial transfusion. The haemoglobin concentration, however, was not maintained and fell steadily for six weeks. After this there was a period of spontaneous improvement in the haemoglobin, leucocytes and platelets, though at no time was any significant reticulocytosis found. Immediately before his second major epistaxis there were again indications of haematological relapse. In the intermediate phase the only incidents were minor epistaxes and on one occasion brisk haematuria. The second major epistaxis was associated with coryza and was so severe that he was in extremis from exsanguination although arrangements for immediate admission and transfusion had previously been made for just this emergency.

It was decided, therefore, that splenectomy should be undertaken since no other form of treatment offered any protection against haemorrhage.

The operation was carried out on March 10, 1954, by Mr. Laurenson and proceeded uneventfully. On removal the spleen appeared normal and was of normal size.
On the second post-operative day the platelet count rose to 152,000 , but thereafter fell rapidly to 70,000 .

On the fourth day he began to vomit and this persisted in spite of treatment. Two days later he had repeated haematemeses and his condition deteriorated. He died on the ninth post-operative day.

Post-mortem Examination. The heart was of normal size for his age (weight $70 \mathrm{~g}$.) and no congenital or other abnormality was identified in it or the great vessels.

Patchy haemorrhagic bronchopneumonia was present in the lower lobes of both lungs. Microscopically there was much extravasation of red cells into the alveolar exudate. The air passages and pleural surfaces were normal.

The stomach, duodenum, jejunum and ileum were greatly dilated, the ileum being three times its normal diameter. There was no evidence of excessive bleeding in the region of the operation.

The liver was normal in size (weight $430 \mathrm{~g}$.), but pale on section, microscopically showing fatty change. The gall bladder and pancreas were normal.

The right kidney (weight $\mathbf{4 0}$ g.) was normal in position, orientation and blood supply. The left kidney (weight 35 g.) was normal in size and appearance, but was situated on the pelvic brim $2.5 \mathrm{~cm}$. below the aortic bifurcation. The renal artery on this side arose at the bifurcation and the renal vein emptied into the common iliac vein. The kidney was rotated with its pelvis lying anteriorly. The ureter, which was naturally short, descended anteriorly to enter the bladder in the normal position. The bladder and genitalia were normal.

The adrenal glands were present in the usual site and were histologically normal.

The skull, meninges, basal arteries, brain, ventricular system and the venous sinuses were normal for a boy of his age.

The lymph nodes were normal.

\section{Discussion}

The conditions of the children whose cases are described fulfil the diagnostic criteria necessary for classification as examples of the syndrome described by Fanconi (1927) in that they showed hypoplastic anaemia, skeletal deformities and abnormal pigmentation.

Haemorrhages and anaemia were the presenting and outstanding symptoms and were the features which governed management. Although the bleeding and clotting times remained normal the platelet counts were invariably diminished. Moreover, the megakaryocytes were so reduced in number that differential counts were not practicable. The erythrocytes were macrocytic with marked anisocytosis and polychromasia. On no occasion was the reticulocyte count found to be raised in Case 2, but in Case 1 a reticulocytosis varying between $1.8 \%$ and $6.8 \%$ was present. There was no erythroid hyperplasia in Case 2, nor in the first examination in Case 1. The second examination 
in Case 1, however, showed evidence of erythroid activity. Evidence of haemolysis in vivo, as judged by splenomegaly, reticulocytosis and raised serum bilirubin, was lacking. It was, nevertheless, decided to carry out splenectomy since the bone marrow was merely hypoplastic as judged by the specimens taken and not completely aplastic-a difference in degree which is held to be important in determining the effect of splenectomy (Reinhold, Newmark, Lightwood and Carter, 1952). In their patient on whom splenectomy was carried out, there was no initial reticulocytosis nor erythroblastic hyperplasia and it was thought that hypersplenism might be a factor, but after operation improvement was not maintained.

The patients reported by Dacie and Gilpin (1944) remained well after splenectomy, though the authors were cautious in concluding that the remission could with certainty be attributed to the operation. In their case there was evidence of excessive haemolysis in that rapid auto-haemolysis was observed in vitro; in addition there was a reticulocytosis and the marrow showed erythroblastic hyperplasia.

The case reported by Estren, Suess and Dameshek (1947) was also benefited at least temporarily by splenectomy. In this instance there was a significant reticulocytosis ranging from $2 \%$ to $11 \%$ before operation and improvement, though small, was maintained for two months, beyond which time no findings are reported.

Rohr's (1949) case, which was not benefited by operation, had no reticulocytosis and very few megakaryocytes in the bone marrow. The marrow picture, however, was not typical of aplastic anaemia because plasmocytes, mast cells and fibrocytes predominated. The blood picture was also unusual because the osmotic fragility of the red cells was increased, and it is therefore doubtful if his case falls into the category described by Fanconi.

The case reported by Silver, Blair and Kempe (1952) had no reticulocytosis at the time of operation and no improvement followed in either platelet count or the haemorrhagic tendency.

The experience of Estren and Dameshek (1947), in successfully abolishing the haemorrhagic tendency in a child suffering from familial hypoplastic anaemia not of the Fanconi type by removal of the spleen, is of interest and relevant to the present discussion. The reticulocyte count, which was initially elevated, fell to normal after operation, the erythrocyte count increased from $1,380,000$ to $2,450,000$ per c.mm., the haemoglobin from 4 to $9 \cdot 8 \mathrm{~g}$., the leucocyte count from 1,800 to 2,400 per c.mm., and the platelet count from 4,140 to 113,000 per c.mm. They found that megakaryocytes were normal in number but showed little platelet formation.

Two further cases which have undergone splenectomy without improvement are recorded, but as full details are not given (Diamond, Smith and Vaughan, 1954; van Leeuwen, 1933), they are not discussed here.

It is thus apparent from consideration of these patients on whom splenectomy has been performed that the degree of hypoplasia judged by examination of the marrow is insufficient evidence upon which to differentiate suitable from unsuitable cases.

Only two of the seven patients with Fanconi's syndrome improved after operation; these patients differed from the remainder in having significant and persistent reticulocytoses until the time of operation and bone marrow showing erythroid hyperplasia. On the other hand, in those who were not benefited the reticulocyte count was normal or low at the time of operation. The cellularity and quality of the marrow in respect of leucocyte and platelet precursors and the degree of polychromasia in the blood did not bear any apparent relationship to the outcome of the operation.

The reticulocytosis in the successful cases was attributed in one to haemolysis (Dacie and Gilpin), but in the other (Estren, Suess and Dameshek, 1947) haemolysis was not demonstrable. In neither of the present cases was there any evidence of haemolysis and the presence of a mild reticulocytosis in Case 1 implies that the reticulocytosis was a manifestation of regenerative activity of the marrow in response to the stimulus of anaemia. It may therefore be taken as a measure of total (erythroid) marrow output, irrespective of local variations in activity of the marrow from bone to bone. A reticulocyte count that is normal or low by accepted standards is thus a demonstration of total (erythroid) marrow insufficiency, which precludes any increase in the erythrocyte count following splenectomy.

As the condition runs its course, progressively or with remissions, the reticulocyte response diminishes (Silver et al., 1952) pari passu with diminishing erythroblastic activity, and the erythrocyte count can no longer be maintained. In our Case 1 there was apparent improvement following splenectomy, but this was not maintained and it could be argued that this was but part of the natural history of the disease rather than a response to splenectomy.

The benefit after splenectomy is therefore at best temporary and cannot be attributed to correction of the basic defect. In patients who are improved the effect may last for several months, and the benefit persist longer than that following transfusion; at the same time the need for transfusion 
is postponed. It is debatable, however, whether the inconvenience and risk of operation even in suitable cases are warranted by this advantage, which, with the modern techniques and safety of transfusion, is small.

Since other forms of treatment, such as liver extracts, folic acid, iron compounds and cortisone, are without effect, reliance should be placed on repeated blood transfusions as the mainstay of therapy.

\section{Summary}

The clinical and haematological findings in two children suffering from Fanconi's syndrome are described.

The indications for splenectomy as a method of treatment for this condition are considered.

Splenectomy may be beneficial in those cases with evidence of regenerative activity as demonstrated by the presence of erythroid hyperplasia of the bone marrow and reticulocytosis in the blood. The benefit is short-lived.

Splenectomy brings no improvement in those cases which show no evidence of regenerative activity and in which the reticulocyte count is not raised.

We acknowledge with thanks the assistance of our colleagues, Dr. E. C. Dawson and Dr. Keith Randall, and Dr. J. Dales, for carrying out the haematological examinations.

\section{REFERENCES}

Dacie, J. V. and Gilpin, A. (1944). Archives of Disease in Childhood,

Diamond, L., Smith, N. J. and Vaughan, V. C. (1954). In Textbook of Pediatrics, 6th ed., ed. Nelson, W. E., p. 955. Philadelphia.

Estren, S. and Dameshek, W. (1947). Amer, J. Dis. Child., 73, 671. , Suess, J. F. and Dameshek, W. (1947). Blood, 2, 85 . Fanconi, G. (1927). Jb. Kinderheilk, 117, 257.

Leeuwen, H. C. van (1933). Folia, haemat., Lpz., 49, 434.

Reinhold, J. D. L., Neumark, E., Lightwood, R. and Carter, C. $O$. (1952). Blood, 7, 915.'

Rohr, K. (1949). Ibid., 4, 130. Child., 83, 14. 